Rezime:

Pukovnik dr Miroslav Radosavljlević, dipl. inž. Vojna akademija

U radu su prikazane sile i momenti koji deluju na podvodni projektil u uslovima statičke $i$ dinamičke stabilnosti $i$ izvedene su jednačine kretanja. Takođe, dati su modeli za računanje sila i momenata projektovanih na ose vezanog koordinatnog sistema projektila.

Ključne reči: podvodni projektil, sile i momenti, statička i dinamička stabilnost.

\title{
FORCES AND MOMENTS AFFECTING UNDERWATER PROJECTILE MOBILITY
}

Summary:

The forces and moments affecting an underwater projectile under conditions of static and dynamic stability are presented and the equations of movement are derived. The models for calculating the forces and moments expressed in the body - fixed coordinate system of the underwater projectile are given as well.

Key words: underwater projectile, forces and moments, static and dynamic stability.

\section{Uvod}

Krećući se kroz vodu projektil sa vodom čini složeni hidrodinamički sistem. Određivanje sila i momenata koje deluju na projektil nije nimalo lak zadatak. Pre svega, neophodno je da se sve sile i njihovi momenti prepoznaju, a zatim da se odrede.

Iz hidrodinamike je poznato da se u spoljašnje sile koje deluju na kruto telo svrstavaju sve sile neinercione prirode i one sile kod kojih je inerciono delovanje vode zanemarivo. Sve te sile mogu se podeliti u sledeće grupe:

- viskozna, rezultujuća hidrodinamička sila $\vec{F}_{H}\left(X_{H}, Y_{H}, Z_{H}\right)$, koja deluje na trup podvodnog projektila, a centar dejstava joj je u centru mase istisnine $c_{B}\left(x_{C B}, y_{C B}, z_{C B}\right)$, 
- porivna sila propulzije $T=X_{p}$ (koja deluje u smeru $x$ ose) i momenat rotacije propelera $\Delta \vec{Q}=-\vec{K}_{p x}$,

- sile upravljanja koje nastaju otklonom kormila $Y_{R V}$ i $Z_{R H}$ i elerona $X_{e}$,

- sila hidrostatičkog uzgona $\vec{F}_{B}$ i razne poremećajne sile $\vec{F}_{A}\left(X_{A}, Y_{A}, Z_{A}\right)$.

Kretanju podvodnog projektila kroz vodu suprotstavljaju se hidrodinamičke sile koje su nepoželjne i ne mogu se ukloniti. Tim silama se suprotstavljaju sile koje nastaju otklonom kormila i elerona s namerom da se prethodne neutrališu. Međutim, pošto se njihova pojava dešava sa izvesnim zakašnjenjem dolazi do poremećajnog kretanje podvodnog projektila. Pojava nepoželjnih sila dovodi do stvaranja obrtnih momenata koji nastoje da zaokrenu projektil u stranu delovanja tih sila. Projektil mora da poseduje sposobnost da se suprotstavi tim nepoželjnim silama. Štaviše, da nakon prestanka delovanja tih sila stvori takav momenat da se sistem vrati u ravnotežno stanje. Ovakve sposobnosti projektila karakterišu njegovu stabilnost. Prema silama koje deluju na projektil razlikuju se dve vrste stabiliteta: statički i dinamički.

\section{Statički stabilitet}

Statički stabilitet podrazumeva mirovanje podvodnog projektila $\mathrm{u}$ vodi i delovanje dve sile: sile težine $\vec{G}$ i sile uzgona $\vec{F}_{B}$.

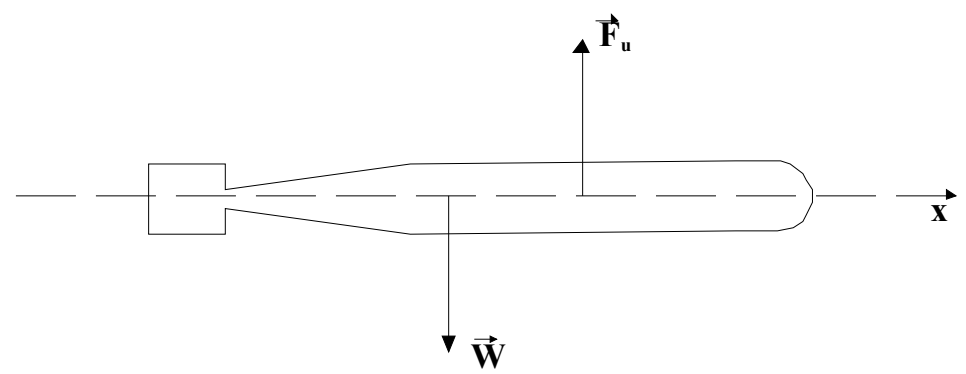

Slika 1 - Grafički prikaz delovanja sile težine i uzgona na projektil koji miruje u vodi

Sa slike 1 vidljivo je da hvatišta sile težine i uzgona ne leže u istoj tački. Hvatište sile težine $G$ se menja tokom kretanja projektila. Uzajamno delovanje sila težine i uzgona menja se tokom vremena (putanje podvodnog projektila).

Položaj hvatišta sila uzgona i težine postavlja se prema proračunu da bi se ostvario uzdužni i poprečni stabilitet podvodnog projektila. Moguće pozicije hvatišta sila prikazane su na slici 2. 


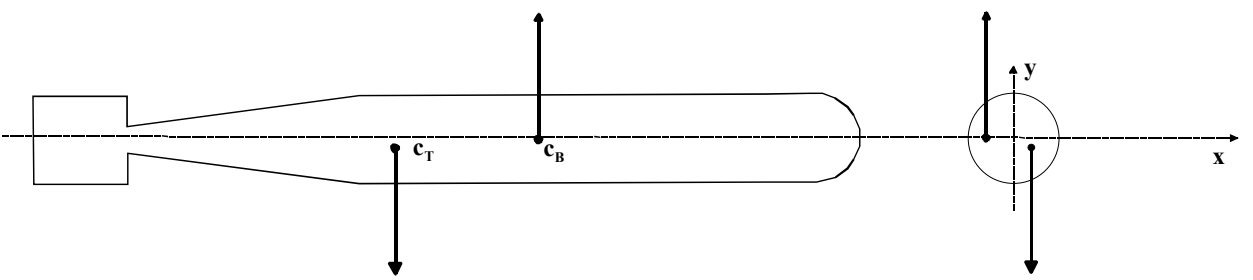

Slika 2 - Grafički prikaz hvatišta sila uzgona u horizontalnoj i vertikalnoj ravni

Osnovni uzrok ovako postavljenih hvatišta je potreba da se delovanju nekih spoljnih sila stvara protivmomenat silama uzgona i težine koji će nakon prestanka delovanja nepoželjnih sila vratiti projektil u ravnotežno stanje.

Ovakvo svojstvo je specifično samo za podvodni projektil. Ni jedan drugi projektil nema to svojstvo. Upravo ova prednost podvodnog projektila omogućuje mu da se njegova upotreba može proširiti u taktičkom smislu. Zato danas u svetu postoje oružja zvana projektil - mina ili mina - projektil. $\mathrm{U}$ pogodnom trenutku projektil se koristi kao klasični podvodni projektil, a u drugom kao mina koja u pasivnom stanju „čeka“ nailazak broda - cilja.

\section{Hidrodinamičke sile podvodnog projektila}

Rezultujuća hidrodinamička sila $\vec{F}_{H}\left(X_{H}, Y_{H}, Z_{H}\right)$ nastaje kretanjem podvodnog projektila u realnoj vodi. Ukoliko bi voda bila idealna, bez viskoziteta, tada bi pri oplakivanju glatke površine tela strujanje bilo jednoliko pravolinijsko, a brzina bi u svim tačkama strujanja bila jednaka. Čestice vode klizile bi po površini tela podvodnog projektila bez ikakvog otpora. U realnoj vodi određenog viskoziteta raspored strujanja ima oblik kao na slici $3 a$.

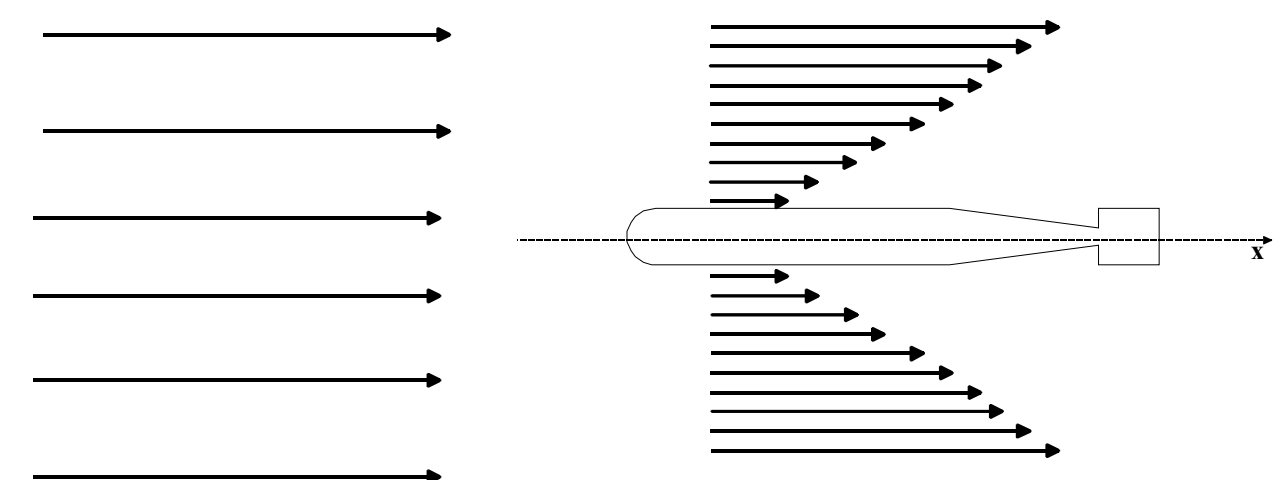

Slika 3a - Raspored brzine strujanja vode uz površinu tela podvodnog projektila 
U neposrednoj blizini tela podvodnog projektila voda ima brzinu nula, a sa udaljavanjem od nje brzina se povećava sve do brzine strujanja $U$. Uloga viskoziteta se ogleda kao kočenje čestica vode, što je rezultat delovanja unutrašnjih sila trenja ili viskoziteta vode. Sile unutrašnjeg trenja određuju se tangentama na površinu tela pritiscima $\vec{\tau}$. Kada se čestice vode kreću u paralelnim slojevima, tangencijalni pritisak određuje se izrazom Njutna:

$\vec{\tau}=-\mu \cdot \frac{\partial \vec{V}}{\partial n}$,

gde su: $\mu$ - koeficijent viskoziteta i $\frac{\partial \vec{V}}{\partial n}-$ gradijent brzine po spoljašnjoj normali $n$.

$\mathrm{Na}$ projektil, pored tangencijalnog pritiska, deluju i normalni pritisci koji se javljaju usled promene brzine čestice vode koje oplakuju telo. Promena brzine strujanja, prema Bernulijevom zakonu, stvara hidrodinamički pritisak na trup podvodnog projektila. Za tačke raspoređene na istoj dubini vode Bernulijeva jednačina može se pisati u obliku:

$\vec{P}=\vec{P}_{0}+\frac{\rho}{2} \cdot \vec{U}^{2} \cdot\left[1-\left(\frac{\vec{V}}{\vec{U}}\right)^{2}\right]$,

gde su: $\vec{P}_{0}$ - hidrostatički pritisak na određenoj dubini $\left[\frac{N}{m^{2}}=P a\right],-$ brzina protoka vode, $\vec{P}$ - hidrodinamički pritisak i $\vec{V}$ - brzina u datoj tački.

Pri kretanju podvodnog projektila na svaku njegovu elementarnu površinu deluje normalna $(\vec{P} \cdot d S)$ i tangencijalna $(\vec{\tau} \cdot d S)$ sila, što je ilustrovano slikom 3b.

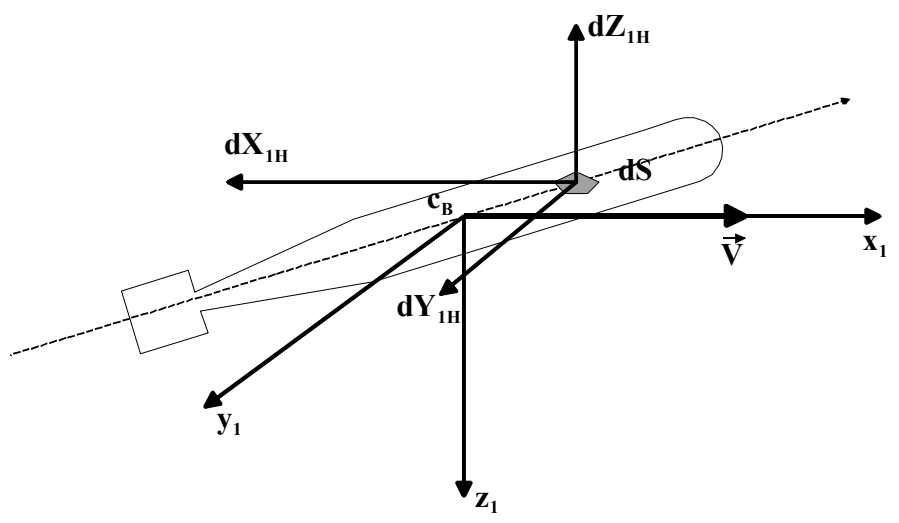

Slika $3 b$ - Hidrodinamičke sile na elementarnu površinu podvodnog projektila 
Projekcija ovih sila na ose koordinatnog sistema brzine su:

$$
\begin{aligned}
& d \vec{X}_{1 H}=\left[\vec{P} \cdot \cos \left(\vec{P}, x_{1}\right)+\vec{\tau} \cdot \cos \left(\vec{\tau}, x_{1}\right)\right] d S \\
& d \vec{Y}_{1 H}=\left[\vec{P} \cdot \cos \left(\vec{P}, y_{1}\right)+\vec{\tau} \cdot \cos \left(\vec{\tau}, y_{1}\right)\right] d S . \\
& d \vec{Z}_{1 H}=\left[\vec{P} \cdot \cos \left(\vec{P}, z_{1}\right)+\vec{\tau} \cdot \cos \left(\vec{\tau}, z_{1}\right)\right] d S
\end{aligned}
$$

Integraljenjem izraza (3) po celoj površini podvodnog projektila dobijaju se izrazi za uzdužnu $\vec{X}_{1 H}$, bočnu $\vec{Y}_{1 H}$ i poprečnu $\vec{Z}_{1 H}$ (u smeru visine trupa torpeda) hidrodinamičku silu na trup podvodnog projektila:

$$
\begin{aligned}
& \vec{X}_{1 H}=\iint_{S}\left[\vec{P} \cdot \cos \left(\vec{P}, x_{1}\right)+\vec{\tau} \cdot \cos \left(\vec{\tau}, x_{1}\right)\right] d S \\
& \vec{Y}_{1 H}=\iint_{S}\left[\vec{P} \cdot \cos \left(\vec{P}, y_{1}\right)+\vec{\tau} \cdot \cos \left(\vec{\tau}, y_{1}\right)\right] d S . \\
& \vec{Z}_{1 H}=\iint_{S}\left[\vec{P} \cdot \cos \left(\vec{P}, z_{1}\right)+\vec{\tau} \cdot \cos \left(\vec{\tau}, z_{1}\right)\right] d S
\end{aligned}
$$

U praksi se koriste drugačiji izrazi. Naime, izrazi pod integralom svode se na bezdimenzioni broj. Za dobijanje jednostavnijeg izraza koristi se izraz brzinskog pritiska datog u sledećoj formi:

$$
\frac{\rho}{2} \cdot \vec{V}^{2}
$$

gde su: $\vec{V}-$ brzina podvodnog projektila $[\mathrm{m} / \mathrm{s}]$ i $\rho$ - gustoća vode $\left[\mathrm{kg} / \mathrm{m}^{3}\right]$

Nakon transformacije izraza (4) dobija se sledeći oblik:

$$
\vec{X}_{1 H}=\frac{\rho}{2} \cdot \vec{V}^{2} \cdot S \cdot \iint_{S}\left[\frac{\vec{P}}{\frac{\rho}{2} \cdot \vec{V}^{2}} \cdot \cos \left(\vec{P}, x_{1}\right)+\frac{\vec{\tau}}{\frac{\rho}{2} \cdot \vec{V}^{2}} \cdot \cos \left(\vec{\tau}, x_{1}\right)\right] \frac{d S}{S} .
$$


Ako se podintegralni izraz obeleži sa $C_{x}$, tada izraz (6) poprima sledeći oblik:

$$
\begin{aligned}
& \vec{X}_{1 H}=\frac{\rho}{2} \cdot \vec{V}^{2} \cdot S \cdot C_{x} \\
& \vec{Y}_{1 H}=\frac{\rho}{2} \cdot \vec{V}^{2} \cdot S \cdot C_{y} . \\
& \vec{Z}_{1 H}=\frac{\rho}{2} \cdot \vec{V}^{2} \cdot S \cdot C_{z}
\end{aligned}
$$

Bezdimenzione veličine $C_{x}, C_{y}, C_{z}$, zovu se koeficijenti uzdužne, bočne i poprečne sile. Suština određivanja sila je u određivanju navedenih bezdimenzionih koeficijenata eksperimentalno na pravom torpedu ili na modelu u hidrodinamičkim tunelima ili u aerotunelima.

Elementarne sile $\vec{P} \cdot d S$ i stvaraju hidrodinamičke momente u odnosu na koordinatne ose. Ukoliko se označe elementarne površine $d S$ koordinatama $x, y, z$, tada će izraz za moment, na primer u odnosu na osu $O x$, biti:

$d \vec{K}_{1 H}=d \vec{Y}_{1 H} \cdot z-d \vec{Z}_{1 H} \cdot y$.

Integracijom izraza (8) po čitavoj površini podvodnog projektila dobija se izraz u obliku:

$$
\vec{K}_{1 H}=\iint_{S}\left(d \vec{Y}_{1 H} \cdot z-d \vec{Z}_{1 H} \cdot y\right) d S .
$$

Radi svođenja na bezdimenzioni oblik potrebno je podintegralni izraz pomnožiti i podeliti sa konstantnim veličinama $\frac{\rho}{2} \cdot \vec{V}^{2}, S, L . \cup$ tom slučaju izraz (9) poprima sledeći oblik:

$$
\vec{K}_{1 H}=\frac{\rho}{2} \cdot \vec{V}^{2} \cdot S \cdot L \iint_{S}\left[\frac{d \vec{Y}_{1 H}}{\frac{\rho}{2} \cdot \vec{V}^{2}} \cdot \frac{z}{L}-\frac{d \vec{Z}_{1 H}}{\frac{\rho}{2} \cdot \vec{V}^{2}} \cdot \frac{y}{L}\right] \frac{d S}{S} .
$$

Ako se bezdimenzioni koeficijent označi sa $C_{m x}$ dobijaju se izrazi za momente u sledećoj formi: 
$\vec{K}_{1 H}=\frac{\rho}{2} \cdot \vec{V}^{2} \cdot S \cdot L \cdot C_{m x}$

$\vec{M}_{1 H}=\frac{\rho}{2} \cdot \vec{V}^{2} \cdot S \cdot L \cdot C_{m y}$.

$\vec{N}_{1 H}=\frac{\rho}{2} \cdot \vec{V}^{2} \cdot S \cdot L \cdot C_{m z}$

Momenti $K_{1 H}, M_{1 H}, N_{1 H}$, zovu se: moment bočnog nagiba, moment posrtanja i moment zakretanja. Na isti način kao i za koeficijente sila i koeficijenti momenata biće posebno obrađeni u sledećem poglavlju.

\section{Hidrostatički uzgon podvodnog projektila}

Hidrostatička sila $\vec{F}_{B}$ deluje uvek normalno prema gore (ka vrhu podvodnog projektila) i uravnotežuje potpuno ili delimično silu težine podvodnog projektila $\vec{W}=m \cdot \vec{g}$. Hidrostatički uzgon ima hvatište u centru vodene istisnine $c_{B}$ sa koordinatama $u$ opštem slučaju $c_{B}=\left(x_{C B}, y_{C B}, z_{C B}\right)$. Na slici 4 grafički je predstavljeno delovanje sile hidrostatičkog uzgona.

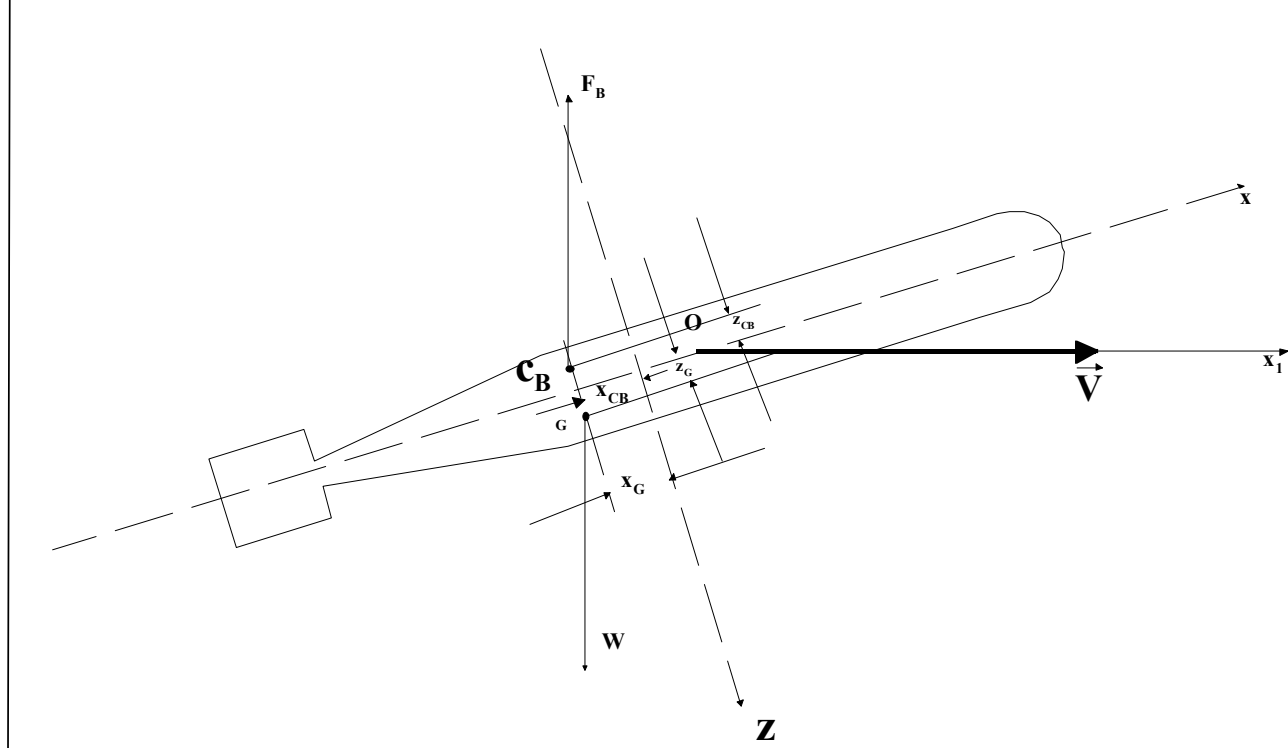

Slika 4 - Grafički prikaz delovanja sile uzgona 
Uobičajeno je da se projektil uravnotežuje, tako da je:

$\vec{W}=\vec{F}_{B}$,

$x_{C B}=x_{G}$. kih sila.

Plovnost podvodnog projektila može se napisati u sledećem obliku:

$$
\left(\vec{W}-\vec{F}_{B}\right)=\left(\vec{W}-\vec{F}_{B}\right) \cdot\left[\begin{array}{c}
-\sin \Theta \\
\sin \varphi \cos \Theta \\
\cos \varphi \cos \Theta
\end{array}\right]
$$

i odgovarajući moment sila:

$$
\vec{M}_{\left(\vec{W}-\vec{F}_{B}\right)}=\left[\begin{array}{c}
\left(-W \cdot z_{G}+F_{B} \cdot z_{C B}\right) \cdot \sin \varphi \cdot \cos \Theta \\
\left(-W \cdot x_{G}+F_{B} \cdot x_{C B}\right) \cdot \cos \varphi \cdot \cos \Theta+\left(-W \cdot z_{G}+F_{B} \cdot z_{C B}\right) \cdot \sin \Theta \\
\left(W \cdot x_{G}+F_{B} \cdot x_{C B}\right) \cdot \sin \varphi \cdot \cos \Theta
\end{array}\right] .
$$

$\mathrm{U}$ dinamičkom modelu, koji je prikazan u nastavku rada, uzeto je da su sile težine i sila uzgona jednake. Ovakva pretpostavka je uobičajena, posebno kod protivpodmorničkih podvodnih projektila gde se napadni ugao reguliše tako da bude približno jednak nuli.

\section{Delovanje propelera podvodnog projektila}

Osnovni pogon torpedu daje par propelera. Ranije je napomenuto da nije obavezan pogon podvodnog projektila propelerima. $U$ radu je razmatran hipotetički projektil sa dva para propelera koji se okreću u suprotnim stranama. Suprotnorotirajući propeleri smanjuju moment zanošenja podvodnog projektila na račun reakcije vode i vrtložnog strujanja vode, čime se povećanja koeficijenta delovanja propelera.

Sila poriva, koju stvaraju propeleri, proporcionalna je gustoći vode $\rho$, brzini okretaja $n$ i prečniku $D_{p}$ propelera. Grafički prikaz delovanja propelera prikazan je na slici 5. 


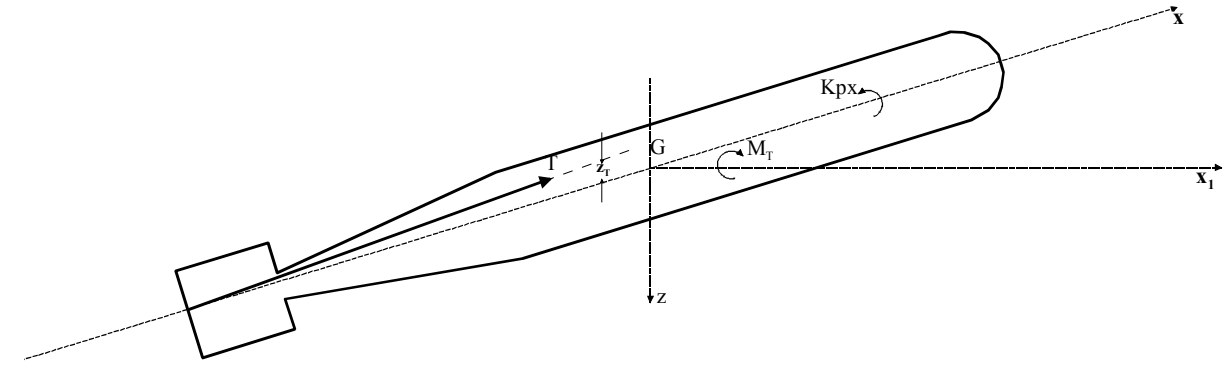

Slika 5 - Grafički prikaz sila koje nastaju delovanjem propelera podvodnog projektila

Sila poriva $P$ i moment otpora $M$ obično se određuju sledećim izrazima:

$\vec{P}=K_{1} \cdot \rho \cdot n^{2} \cdot D_{p}^{4}$,

$\vec{M}=K_{2} \cdot \rho \cdot n^{2} \cdot D_{p}^{5}$.

Ovi izrazi su dobijeni na osnovu teorije sličnosti, gde je u izrazima: $K_{1}$ - koeficijent sile poriva, $K_{2}-$ koeficijent momenta.

$U$ praksi se sila poriva daje sledećim izrazom:

$\vec{T}=\vec{P} \cdot(1-t)=(1-t) \cdot K_{1} \cdot \rho \cdot n^{2} \cdot D_{p}^{4}$,

gde je: $t$ - bezdimenzioni koeficijent smanjenog poriva usled delovanja poriva trupa podvodnog projektila (kreće se u granicama od 0,1 do 0,2).

$\mathrm{Na}$ osnovu procene i saznanja o projektilima u radu je korišćen bezdimenzioni koeficijent $t=0,15$. Takođe, prečnik propelera je usvojen $D_{p}=0,45 \mathrm{~m}$ a broj okretaja $n=17-20 \mathrm{o} / \mathrm{s}$.

Moment sile $\vec{T}$ oko ose Oy je:

$\vec{M}_{T}=z_{T} \cdot \vec{T}$,

gde je: $z_{T}$ - aplikata ose propelera.

lako su propeleri postavljeni $u$ istu osu i bez obzira na to što se okreću u suprotne strane, postoji moment oko Ox ose.

\section{Sile i momenti sila koje stvaraju kormila i eleroni}

Da bi se obezbedile dobre hidrodinamičke karakteristike podvodnog projektila neophodno je uskladiti veliki broj međusobno suprotstavljenih zahteva. Jedan od osnovnih zahteva je izbor optimalnog hidrodinamičkog oblika tela podvodnog projektila. Poželjni hidrodinamički oblik podvodnog projektila podrazumeva dobru usklađenost krstastog nastavka podvodnog projektila i kormila koja se na njemu ugrađuju. U dobrom hidrodinamičkom obliku sa definisanim krstastim nastavkom i njegovim uklapanjem u formu, projektil mora brzo i tačno da odreaguje na otklone kormila. 
Par kormila se postavlja (po jedno sa svake strane trupa) u horizontalnu i vertikalnu ravan. Ukupna sila koja deluje na kormilne površine $\vec{F}_{R V}$ može se rastaviti na silu otklona $\vec{L}_{R V}$ i otpora $\vec{D}_{R V}$ u vezanom koordinatnom sistemu ili normalnu $\vec{F}_{R V N}$ i tangencijalnu komponentu $\vec{F}_{R V T}$ u inercijskom koordinatnom sistemu. $U$ vezanom koordinatnom sistemu podvodnog projektila mogu se napisati izrazi za silu:

$$
\begin{gathered}
\vec{Y}_{R V}=-\vec{L}_{R V}, \\
\vec{X}_{R V}=\vec{D}_{R V} .
\end{gathered}
$$

Na slici 6 grafički je prikazano delovanje komponenata hidrodinamičke sile na kormilnu površinu.

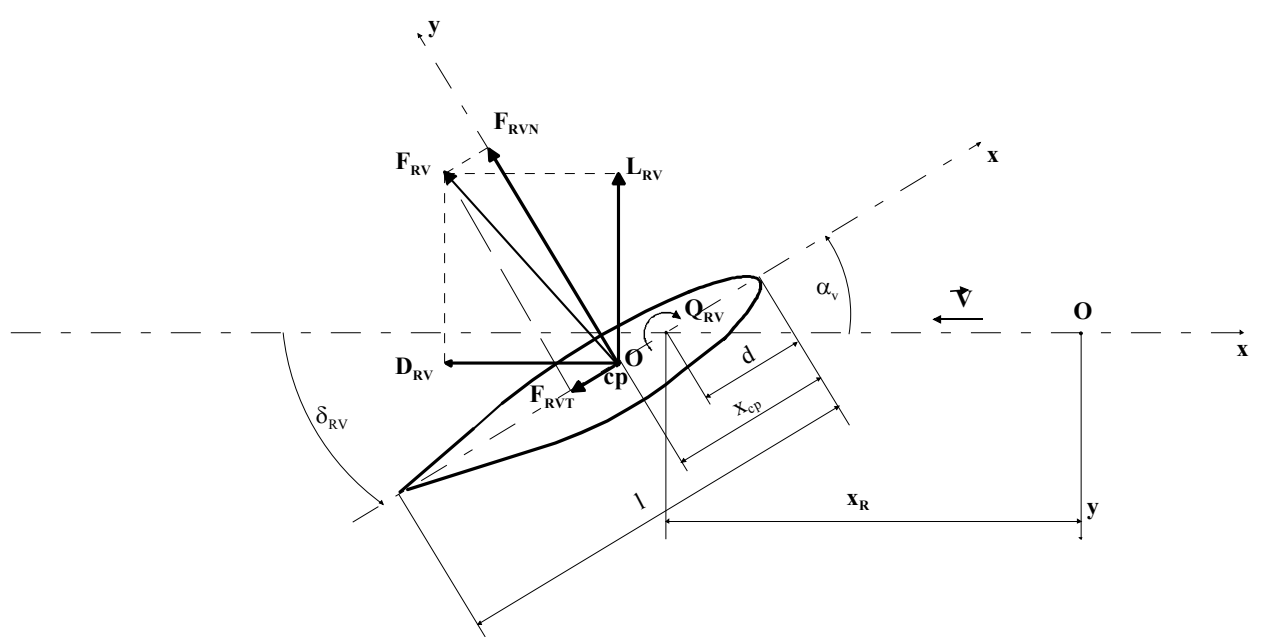

Slika 6 - Grafički prikaz sila koje deluju na kormilne površine

Sila otklona smernog kormila u vezanom koordinatnom sistemu može se računati prema sledećem izrazu:

$\vec{Y}_{R V}=\frac{1}{2} \cdot \rho \cdot \vec{V}^{2} \cdot S_{R V} \cdot C_{V K}$.

Bezdimenzioni koeficijent $C_{V K}$ je funkcija otklona $\delta_{V K}$, ugla zanošenja $\beta$ i brzine kretanja podvodnog projektila:

$C_{V K}=f\left(\delta_{V K}, \beta, V\right)$.

Momenat sile vertikalnih kormila određuje se izrazom:

$\vec{N}_{R V}=x_{R} \cdot \vec{Y}_{R V}$, 
gde je: $x_{R V}$ - rastojanje osovine kormila na $x$ u vezanom koordinatnom sistemu. Koeficijent otpora vertikalnih kormila je:

$C_{m V K}=f\left(\delta_{V K}, \beta, V\right)$.

$\mathrm{Na}$ analogan način određuje se sila uzgona dubinskih kormila:

$\vec{Z}_{R H}=\frac{1}{2} \cdot \rho \cdot \vec{V}^{2} \cdot S_{R H} \cdot C_{V H}$

i odgovarajući momenat:

$M_{R H}=x_{R} \cdot \vec{Z}_{R H}$.

Koeficijent sile otpora horizontalnih kormila je:

$C_{V H}=f\left(\delta_{V H}, \alpha, V\right)$,

a koeficijent otpora momenta nastalog od sile horizontalnih kormila je:

$C_{m V H}=f\left(\delta_{V H}, \alpha, V\right)$.

Uticaj elerona na stabilizaciju poprečnog nagiba ilustrovan je na slici 7.

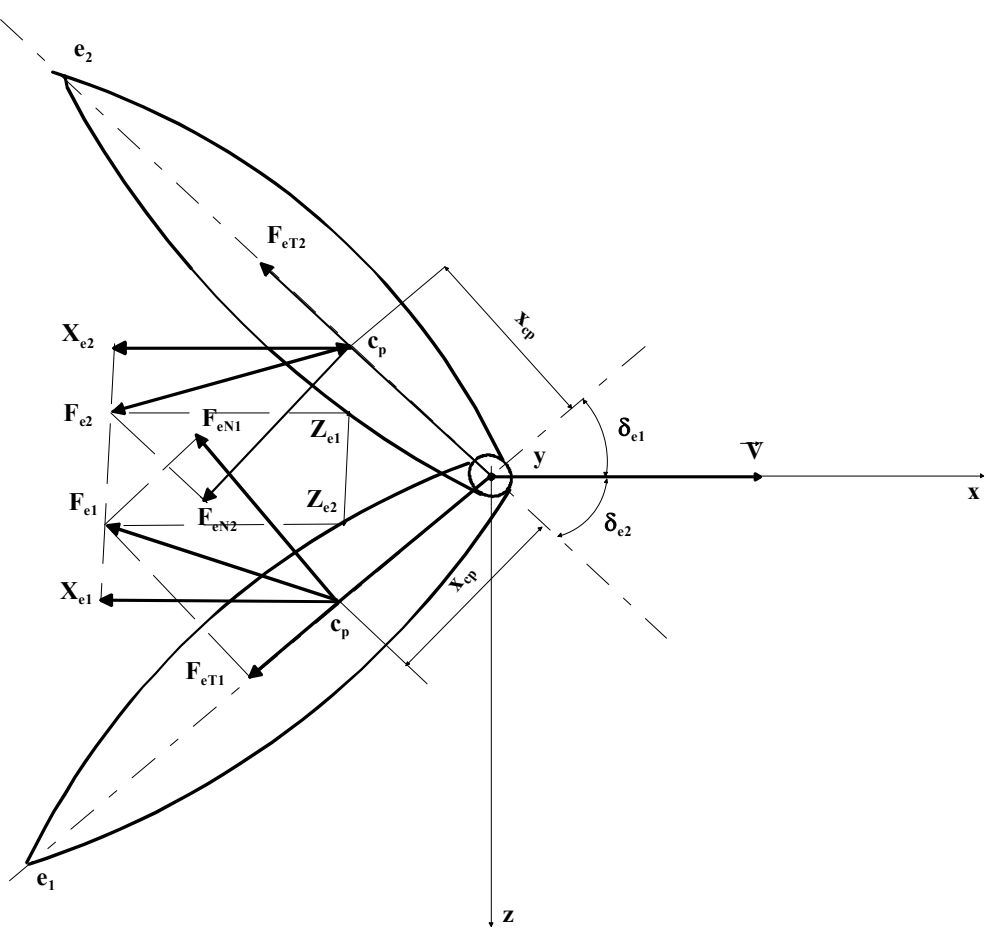

Slika 7 - Grafički prikaz komponenti hidrodinamičkih sila elerona 
Ukupna sila elerona $\vec{F}_{e 1}$ i $\vec{F}_{e 2}$ rastavlja se na silu otpora $\vec{X}_{e 1}$ i $\vec{X}_{e 2}$ i silu uzgona $\vec{Z}_{e 1}$ i $\vec{Z}_{e 2}$ ili na normalnu silu $\vec{F}_{e N 1}$ i $\vec{F}_{e N 2}$ i tangencijalnu silu $\vec{F}_{e T 1}$ i $\vec{F}_{e T 2}$. Sile upravljanja koje deluju na bočni nagib su jednake uzgonske sile $\vec{Z}_{e 1}=\vec{Z}_{e 2}=\vec{Z}_{e}$, koje su posledica otklona elerona $e_{1}$ i $e_{2}$ za ugao $\delta_{e}$ na suprotne strane u odnosu na uzdužnicu podvodnog projektila (Ox ose).

Ukupna otporna sila elerona računa se prema sledećem izrazu:

$\vec{X}_{e}=\vec{X}_{e 1}+\vec{X}_{e 2}=2 \cdot \frac{1}{2} \cdot \rho \cdot S_{e f f} \cdot \vec{V}^{2} \cdot C_{e}$,

gde je: $S_{\text {eff }}$ - efektivna površina elerona gledano u smeru kretanja podvodnog projektila i $C_{e}$ - koeficijent otpora sile, koji je funkcija $C_{e}=f\left(\delta_{e}, V, \alpha\right)$, a dobija se kao i ostali koeficijenti otpora sila.

Moment nagiba sila elerona izračunava se prema izrazu:

$\vec{K}_{e}=2 \cdot \frac{1}{2} \cdot \rho \cdot S_{e f f} \cdot \vec{V}^{2} \cdot y_{e} \cdot C_{m e}$,

gde je: $y_{e}-$ udaljenost od uzdužne ose podvodnog projektila do centra pritiska elerona i $C_{m e}$ - koeficijent otpora momenta bočnog nagiba elerona i funkcija je $C_{m e}=f\left(\delta_{e}, V, \alpha\right)$, a određuje se eksperimentalno kao i ostali koeficijenti.

\section{Poremećajne sile}

Talasi su osnovni spoljni faktori koji utiču na dinamiku kretanja podvodnog projektila. Po fizičkoj prirodi radi se o trodimenzionalnim slučajnim talasima koji se do određenih dubina šire u morskom prostranstvu. Pored ovih, poremećajna strujanja oko podvodnog projektila izazivaju i vertikalna temperaturna i vrtložna strujanja vode. Njihovo delovanje po smeru i jačini su vrlo neizvesni. Pretpostavlja se da slučajni talasi ne prelaze dubine veće od njihove dužine. Talasi na projektil deluju poremećajno u vidu otklanjanja osetljivih elemenata (na primer, na hidrostatske osetljive elemente), čime se menja zadata putanja. Morska struja se menja vrlo sporo. Ukoliko se pretpostavi sinusoidalna promena, treba računati sa periodom od nekoliko sati. Zbog toga se računa, s obzirom na putanju podvodnog projektila od nekoliko minuta, da je struja mora u toku kretanja projektila konstantna za određeno morsko područje. Pretpostavlja se da vodena struja izaziva poremećajne sile samo u $x_{0} y_{0}$ ravni i da joj je smer $\Psi_{S}$, što je ilustrovano na slici 8. 


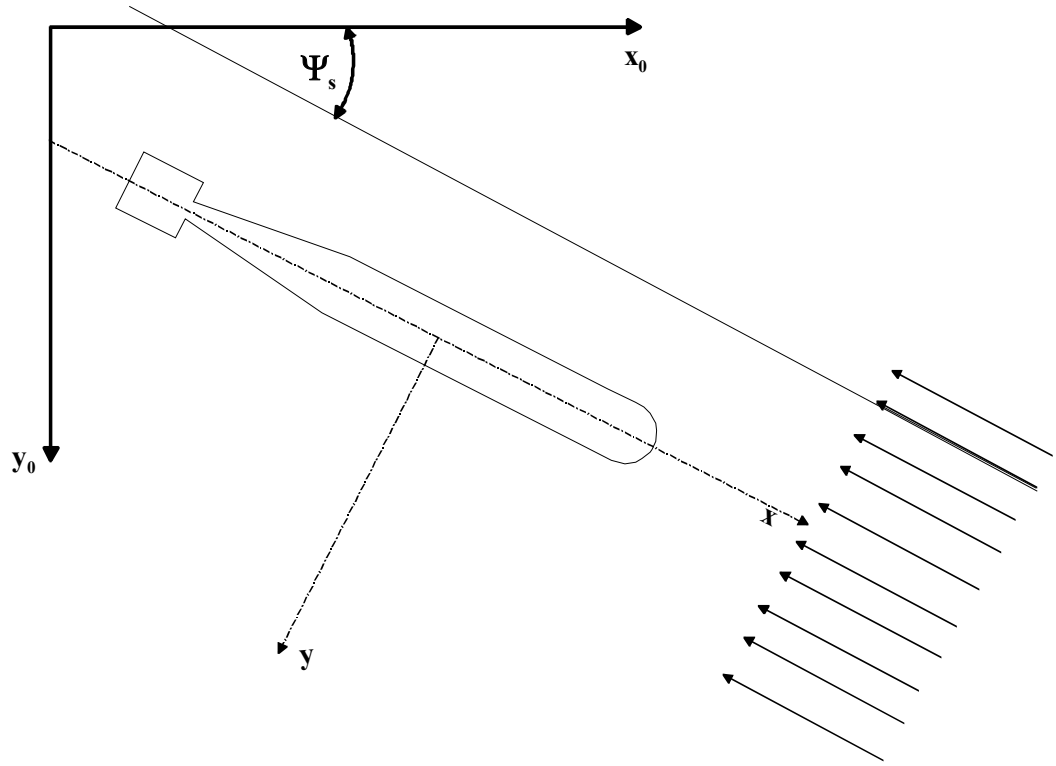

Slika 8 - Grafički prikaz delovanja sila struje mora na projektil u kretanju

Komponente poremećaja u inercijskom koordinatnom sistemu su:

$$
\begin{aligned}
& \Delta U_{x}=\Delta U_{s} \cdot \cos \left(\Psi_{S}-\Psi\right), \\
& \Delta U_{y}=\Delta U_{s} \cdot \sin \left(\Psi_{S}-\Psi\right) .
\end{aligned}
$$

Poremećaj usled temperaturnih i vrtložnih strujanja može biti vrlo različitog karaktera i funkcija je dubine mora. Pretpostavlja se delovanje samo u smeru Oz koordinate i simulira funkcijom:

$$
\Delta U_{z}\left(1-e^{-h}\right) \cdot \sum_{i=1}^{n} k_{S_{i}} \cdot\left(\frac{\sin \left(a_{i} \cdot t\right)}{a_{i} \cdot t}\right) \cdot\left(\frac{\sin \left(b_{i} \cdot t\right)}{b_{i} \cdot t}\right),
$$

gde su: $h$ - dubina kretanja podvodnog projektila, $k_{S_{i}}, a_{i}, b_{i}$-- konstantne veličine sa kojima se učinak $\Delta U_{z}$ u toku vremena $t$ može osetiti uticaj delovanja na projektila i $n$ - ne veći od 3 .

Tokom kretanja projektila ka cilju na njega može da se deluje podvodnom eksplozijom koja može nastati dejstvom dubinskih bombi. Veoma je specifična i vrlo verovatna kao taktički odgovor protivnika na dejstvo podvodnog projektila. Podvodna eksplozija može se simulirati im- 
pulsnom funkcijom prikazanom na slici 9. Delovanje eksplozije simulira se u stvaranju sila $\vec{Y}_{A J}$ i $\vec{Z}_{A J}$ prema sledećoj definiciji:

$\vec{Y}_{A J}=a_{n}, t_{n} \leq t \leq t_{n+1}, n=0, \pm 1, \pm 2, \ldots$.
$\vec{Z}_{A J}=b_{n}, t_{n} \leq t \leq t_{n+1}, n=0, \pm 1, \pm 2, \ldots$.

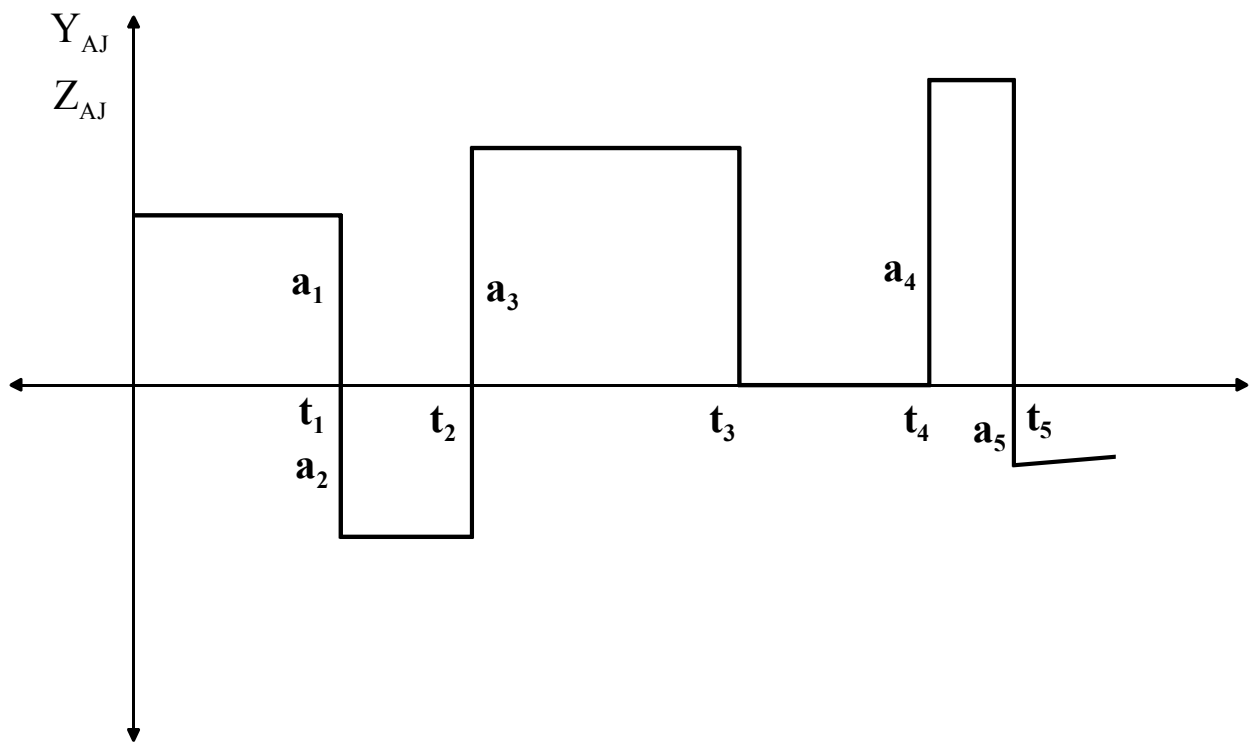

Slika 9 - Grafički prikaz impulsnih sila podvodne eksplozije

\section{Opšti izraz jednačine kretanja podvodnog projektila}

Na osnovu izvedenih opštih karakteristika sila i momenata koje deluju na projektil došlo se do jednačine kretanja podvodnog projektila u vezanom koordinatnom sistemu Oxyz.

Ako koordinatni početak vezanog koordinatnog sistema leži u centru mase podvodnog projektila:

$x_{G}=y_{G}=z_{G}=0$

i ako se odabere da koordinatne ose budu glavne ose inercije:

$I_{x y}=I_{y z}=I_{x z}=0$ 
tada opšti izraz jednačina kretanja podvodnog projektila ima oblik:

$\left[\left(m+\lambda_{11}\right) \cdot \dot{V}_{x}-\left(m+\lambda_{22}\right) \cdot V_{y} \cdot r-\lambda_{26} \cdot r^{2}+\left(m+\lambda_{33}\right) \cdot V_{z} \cdot q+\lambda_{35} \cdot q^{2}\right.$

$\left(m+\lambda_{22}\right) \cdot \dot{V}_{y}+\lambda_{26} \cdot \dot{r}+\left(m+\lambda_{11}\right) \cdot V_{x} \cdot r-\left(m+\lambda_{33}\right) \cdot V_{z} \cdot p-\lambda_{35} \cdot p \cdot q$

$\left(m+\lambda_{33}\right) \cdot \dot{V}_{z}+\lambda_{35} \cdot \dot{q}-\left(m+\lambda_{11}\right) \cdot V_{x} \cdot q+\left(m+\lambda_{22}\right) \cdot V_{y} \cdot p+\lambda_{26} \cdot p \cdot r$

$\left(I_{x x}+\lambda_{44}\right) \div \dot{p}-\left(m+\lambda_{22}\right) \cdot V_{x} \cdot V_{z}-\lambda_{26} \cdot V_{z} \cdot r+\left(m+\lambda_{33}\right) \cdot V_{y} \cdot V_{z}+\lambda_{35} \cdot V_{y} \cdot q-\left(I_{y y}+\lambda_{55}\right) \cdot q \cdot r-\lambda_{35} \cdot V_{z} \cdot r+\left(I_{z z}+\lambda_{66}\right) \cdot q \cdot r+\lambda_{26} \cdot V_{y} \cdot q=$

$\left(I_{y y}+\lambda_{55}\right) \cdot \dot{q}+\lambda_{35} \cdot \dot{V}_{z}+\left(m+\lambda_{11}\right) \cdot V_{x} \cdot V_{z}-\left(m+\lambda_{33}\right) \cdot V_{x} \cdot V_{z}-\lambda_{35} \cdot V_{x} \cdot q+\left(I_{x x}+\lambda_{44}\right) \cdot p \cdot r+\left(I_{z z}+\lambda_{66}\right) \cdot p \cdot r-\lambda_{26} \cdot V_{y} \cdot p$

$\left(I_{z z}+\lambda_{66}\right) \cdot \dot{r}+\lambda_{26} \cdot \dot{V}_{y}-\left(m+\lambda_{11}\right) \cdot V_{x} \cdot V_{y}+\left(m+\lambda_{22}\right) \cdot V_{x} \cdot V_{y}+\lambda_{26} \cdot V_{x} \cdot r-\left(I_{x x}+\lambda_{44}\right) \cdot p \cdot q+\left(I_{z z}+\lambda_{55}\right) \cdot p \cdot q+\lambda_{35} \cdot V_{z} \cdot p$

$=\left[\begin{array}{c}F_{x} \\ F_{y} \\ F_{z} \\ M_{x} \\ M_{y} \\ M_{z}\end{array}\right]$

gde su: $I_{x x}, I_{y y}, I_{z z}$ - momenti inercije trupa podvodnog projektila, $m$ - masa podvodnog projektila, $\lambda_{i k}$ - pridružene mase, $V_{x}, V_{y}, V_{z}$ - projekcije vektora brzine podvodnog projektila, $p, q, r$ - projekcije vektora ugaone brzine podvodnog projektila.

$\mathrm{Na}$ desnim stranama jednačine nalaze se spoljne sile i momenti koje deluju na projektil:

$$
\begin{aligned}
& {\left[\begin{array}{l}
F_{x} \\
F_{y} \\
F_{z}
\end{array}\right]=\left[\begin{array}{c}
-X_{H} \\
Y_{H} \\
Z_{H}
\end{array}\right]+\left(W-F_{B}\right) \cdot\left[\begin{array}{c}
-\sin \Theta \\
\sin \varphi \cdot \cos \Theta \\
\cos \varphi \cdot \cos \Theta
\end{array}\right]+\left[\begin{array}{c}
T \\
0 \\
0
\end{array}\right]+\left[\begin{array}{c}
0 \\
Y_{R V} \\
0
\end{array}\right]+\left[\begin{array}{c}
0 \\
0 \\
Z_{R H}
\end{array}\right]+\left[\begin{array}{c}
-X_{e} \\
0 \\
0
\end{array}\right]+\left[\begin{array}{c}
X_{A} \\
Y_{A} \\
Z_{A}
\end{array}\right]} \\
& {\left[\begin{array}{c}
M_{x} \\
M_{y} \\
M_{z}
\end{array}\right]=\left[\begin{array}{c}
K_{H} \\
M_{H} \\
N_{H}
\end{array}\right]+\left[\left(-W \cdot x_{G}-F_{B} \cdot x_{C B}\right) \cdot \cos \varphi \cdot \cos \Theta+\left(-W \cdot z_{G}-F_{B} \cdot z_{C B}\right) \sin \Theta\right]+} \\
& +\left[\begin{array}{c}
K_{p x} \\
M_{T} \\
0
\end{array}\right]+\left[\begin{array}{c}
0 \\
0 \\
N_{R V}
\end{array}\right]+\left[\begin{array}{c}
0 \\
M_{R H} \\
0
\end{array}\right]+\left[\begin{array}{c}
K_{e} \\
0 \\
0
\end{array}\right]+\left[\begin{array}{c}
K_{A} \\
M_{A} \\
N_{A}
\end{array}\right]
\end{aligned}
$$

gde su:

$X_{H}, Y_{H}, Z_{H}$ - uzdužna, bočna i poprečna ukupna hidrodinamička sila na trup podvodnog projektila,

$W=m \cdot g$ - sila težine podvodnog projektila,

$F_{B}$-- sila hidrostatičkog uzgona,

$\varphi, \Theta$ - ugao bočnog nagiba i trima podvodnog projektila,

$T$ - sila poriva podvodnog projektila, 
$X_{e}$ - sila otpora elerona,

$Y_{R V}$ - sila otklona smernog (vertikalnih kormila),

$Z_{R H}$ - sila horizontalnih kormila,

$X_{A}, Y_{A}, Z_{A}$ - ukupne spoljne poremećajne sile,

$K_{H}, M_{H}, N_{H}$ - ukupni hidrodinamički momenat nagiba, posrtanja i zakretanja,

$K_{p x}$ - moment rotacije propelera,

$M_{T}$ - moment poriva propelera,

$K_{e}$ - moment elerona,

$N_{R V}$ - moment vertikalnih kormila,

$M_{R H}$ - moment dubinskih kormila i

$K_{A}, M_{A}, N_{A}$ - dodatni ukupni poremećajni momenti.

\section{Zaključak}

Na osnovu statičke stabilnosti date su sile koje se uravnotežuju, a konstruktivnom izradom projektila definišu se napadne tačke koje projektilu obezbeđuju potrebnu stabilnost pri delovanju nepoželjnih sila.

Pri kretanju projektila definisane su sile koje nastaju kao posledica reakcije tela projektila, propelera i kormilnih površina, kao i moguće poremećajne sile. Dejstvo navedenih sila razmatrano je u svim ravnima torpeda, na osnovu čega su dati matematički izrazi za njihovo izračunavanje.

U svim izrazima za sile i momente dati su koeficijenti koji su specifični za oblik i način kretanja podvodnog projektila. Da bi se dati sistem jednačina mogao rešavati neophodno je identifikovati koeficijente, što je poseban problem i tema nekog narednog rada.

\section{Literatura}

[1] Podobrij, G. M. i dr., Теоретические основи торпедного оружиа, Боенное издатељство Министарства оборони СССР, 1969.

[2] Patrašev, A. N. i dr., Прикладнаја гидромеханика, Министраство оборони СССР, Moskva 1970.

[3] Voronjec, K. Obradović, N., Mehanika fluida, Građevinska knjiga, Beograd 1979.

[4] Grupa autora, Podmornički trenažer, matematički model podmornice, Brodarski institut Zagreb, 1980. 